\section{Balancing the availability of opioids- the pendulum is swinging again}

\author{
Phil Wiffen
}

Strong opioids are under attack again and pharmacists need to be aware of the issues in order to balance regulatory concerns with meeting the needs of patients in severe pain. The main pressures are coming from the USA but there are increasing clinical concerns in Europe as well.

The US situation has become very political with President Obama making statements such as: "Four out of five heroin users started out by misusing prescription opioids" and "120 Americans die every day from drug overdoses-most involving legal prescription drugs" Of course these are only half truths. The reality is that heroin use has been a problem in the US for decades. On the other hand there is no doubt that prescription opioids have been diverted by patients and family members.

The International Narcotics Board ${ }^{1}$ states: "The primary objective of the 1961 and 1971 Conventions is to ensure the availability of controlled drugs for medical and scientific purposes and to prevent the non-medical use of those drugs.”

Few hospital pharmacists have a role in misuse legislation but the key issue for us surrounds the clinical use of strong opioids and we have a role to promote the appropriate use of opioids for both cancer related pain and chronic noncancer pains. The key task here is the promotion of appropriate use.

For cancer pain, strong opioids are frequently required and there is good evidence to support their use. The general rule is to titrate doses until either pain relief is achieved or adverse effects become intolerable. There is no good evidence to support the notion that cancer patients will become addicted to these drugs but doses will probably increase as the tumour progresses. The tragedy is that fear of addiction has led many developing countries to severely restrict opioids so that in practice they are either not

Correspondence to Professor Phil Wiffen, Pain Research Unit, Churchill Hospital, Old Rd, Oxford OX3 7LE, UK; phil.wiffen@ndcn.ox.ac.uk available or only available in sub therapeutic doses. Such an approach, in my view, is morally indefensible.

Using strong opioids for chronic nonmalignant pain is much more difficult. The reality is that we don't have ideal analgesics as yet and new products on the market have yet to prove superiority over what we have. When a patient presents with chronic pain (persistent pain for at least 3 months) there are few choices. NSAIDs are a possibility but have limitations and are unlikely to be suitable for the elderly. The temptation to prescribe opioids for patients who are tearfully in severe pain is great but fraught with problems. In many cases although opioids seem a logical choice, they may not provide the expected pain relief. We know there is little evidence for effectiveness in neuropathic pains due to nerve damage such as post herpetic neuralgia and even in musculoskeletal pains such as the common condition of back pain, they may have limited effect. In the pain clinic here in Oxford there is a constant challenge of patients on high doses of strong opioids who still report high levels of pain but patients are reluctant to stop their drugs for fear of the pain becoming worse. In addition there are strong possibilities of unwanted adverse effects. A recent paper by Ray et $a l^{2}$ in $J A M A$ describes a large cohort study matching patients on strong opioids for chronic non cancer pain with a control group (anti-epileptics or antidepressants). They discovered that there was a significant increase in all-cause mortality in the opioid group largely due to cardiovascular causes. The choice of drugs in the control group is slightly odd and it is a shame that there was no comparison with an NSAID group. In the study there was no assessment of what pain relief was obtained.

A key role is therefore to promote the responsible use of opioids in some cases promoting their use for cancer pain and ensuring that doses are adequate to meet patients' needs. In other areas pharmacists may need to play a cautionary role such as in non-cancer pain to ensure that patients are appropriately assessed and that the implications of commencing opioids is fully understood.

A useful paper by Scholten and Henningfield ${ }^{3}$ makes recommendations for the responsible prescribing of opioids. I have adapted these and added my own:

1. Follow the dosage guidelines as recommended in guidelines

2. Assess the patients pain and functioning regularly and adjust dosage accordingly for optimal pain relief

3. Avoid prescription of more than is necessary to treat pain in order to avoid diversion or accumulation of stock

4. Avoid under treatment of pain in order to prevent 'doctor shopping'

5. Instruct the patient and any caregivers to store opioid medicines safely and out of reach of others

6. Instruct the patient and any caregivers how to safely dispose of unused medicines so as to prevent medicines being diverted to illicit markets

7. At the first prescription discuss with the patient a plan for stopping opioids if they are ineffective.

8. Be willing to stop opioids if they are not working even if you have nothing else to offer.

9. Believe what patients say about their pain and try and find ways to treat the pain. Remember that non pharmacological options are available.

\section{EAHP Statement 6: Education and} Research

\section{Competing interests None declared.}

Provenance and peer review Commissioned; internally peer reviewed.

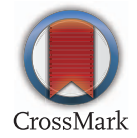

To cite Wiffen P. Eur J Hosp Pharm 2016;23:249.

Eur J Hosp Pharm 2016;23:249.

doi:10.1136/ejhpharm-2016-001076

\section{REFERENCES}

1 International Narcotics Control Board. Report of the International Narcotics Board 2008. E/INCB/2008/1.

2 Ray WA, Chung CP, Murray KT, et al. Prescription of long-acting opioids and mortality in patients with chronic noncancer pain. JAMA 2016;315:2415-23.

3 Scholten W, Henningfield JE. Negative outcomes of unbalanced opioid policy supported by clinicians, politicians, and the media. J Pain Palliat Care Pharmacother 2016;30:4-12. 